RESEARCH ETHICS

\title{
"Hello, hello-it's English I speak!": a qualitative exploration of patients' understanding of the science of clinical trials
}

\author{
M Stead, D Eadie, D Gordon, K Angus
}

\begin{abstract}
See end of article for
authors' affiliations

.....................

Correspondence to:

Martine Stead, Deputy

Director, Institute for Social

Marketing, University of

Stirling and the Open

University, Stirling FK9

4LA, UK; martine.stead@

stir.ac.uk
\end{abstract}

Received 28 October 2004

Accepted for publication

19 February 2005
J Med Ethics 2005;31:664-669. doi: 10.1136/jme.2004.011064

Informed consent may be seriously compromised if patients fail to understand the experimental nature of the trial in which they are participating. Using focus groups, the authors explored how prospective trial participants interpret and understand the science of clinical trials by using patient information sheets relative to their medical condition. An opportunity was provided to hear in the patients' own words how they interpret the information and why there is variable understanding. Respondents struggled to comprehend the meaning and purpose of concepts such as randomisation and double blinding, and found them threatening to their ideas of medical care. Suggestions are made about how to improve the national guidelines on written information for trial participants and pretesting of the information sheets is advocated.
A particular challenge for informed consent to taking part in a clinical trial is that of ensuring that patients understand the scientific nature of the trial. Random allocation of participants to different treatments is considered justifiable ethically only if a state of uncertainty exists about which treatment is better ("equipoise"). It is therefore important that participants understand that a trial involves randomisation and that they also understand, and accept, the reason for the randomisation. ${ }^{12}$ Where this aspect of a trial is not understood, patients may be unable to perceive the difference between research and standard care, and may labour under a "therapeutic misconception" - that is, the belief that treatment is allocated on a therapeutic basis. ${ }^{3}$ This potential misconception has clear implications for informed consent.

Frequently, however, studies have demonstrated that understanding of these concepts is patchy. ${ }^{4}$ A study of Australian oncology outpatients found that only $43 \%$ knew that treatment would be decided by chance in a randomised controlled trial (RCT), and nearly three-quarters thought that their doctor would make sure they "got the best of the treatments" available (p. 38). ${ }^{5}$ In another study, nearly a quarter of the respondents believed that doctors "privately [know] which one of the investigated treatments is best" in an RCT (p. 969). ${ }^{6}$ Other studies have shown similar levels of misunderstanding. ${ }^{78}$ These findings suggest that a large proportion of prospective trial participants do not understand, or believe, information about randomisation when it is presented to them.

Similar findings have been shown in relation to the concept of equipoise. One study examined public understanding of the idea of equipoise by presenting information suggesting that a new treatment was promising, but that there was no evidence about whether it was better or worse than standard treatment. ${ }^{9}$ Despite this explanation, over half the respondents believed that the new treatment must be superior, and only $38 \%$ correctly understood the equipoise. Of the same study it was noted that, had it been a real trial, "the consent these people gave may have been 'informed', but the information was certainly not properly comprehended" (p. 1047). ${ }^{10}$

Uncertainty about randomisation and equipoise has been found to exist even among actual trial participants, who might be expected to have better understanding than the general public. Simes et al ${ }^{11}$ assessed knowledge levels among patients in "live" randomised oncology trials and found that, even when trial participants were given an explicit explanation of randomisation, more than half "still failed to understand" this element (p. 1067). ${ }^{11}$ In a beta-blocker trial, only $42 \%$ of patients were aware that allocation to experimental or control therapy was made by chance, and even patients who apparently fully understood the design of the study occasionally implied that they "believed that [the trial] was really a therapeutic programme" (p. 300)..$^{12}$

Despite a plethora of studies quantifying patients' poor understanding of the science of clinical trials, relatively few have attempted to explore how patients interpret these concepts and why understanding seems poor. Quantitative methods such as surveys or experiments can compare levels of knowledge in different groups of patients, or examine whether different ways of framing information lead to better comprehension. ${ }^{2}{ }^{13}$ However, such studies are less helpful for explaining why patients have such varying understandingthat is, whether the difficulties stem from the intrinsic complexity of the science itself, from badly written patient information sheets, or from the social context and the emotional stresses surrounding the decision to participate in a trial. Nor do they allow researchers to hear patients' voices-that is, how people, in their own words, really interpret and feel about complex clinical information. Qualitative research is able to provide these insights. ${ }^{14-17}$ This qualitative study, part of a larger study into the role of written information in the informed consent process commissioned by NHS Lanarkshire Research Ethics Committee (REC), explored how prospective trial participants interpret

Abbreviations: RCT, randomised controlled trial; REC, research ethics committee 
and understand the science of clinical trials using patient information material relevant to their medical condition.

\section{METHOD}

Four focus groups were conducted, each comprising between four and seven participants. Ten women and 14 men (aged 42-77 years) participated. They were from a range of occupational backgrounds including being unemployed and retired. The sample was drawn from patients with type I and II diabetes in Lanarkshire. Potential participants were screened at their annual consultant review using three selection criteria: aged over 18 years, diagnosed with type I or II diabetes more than 12 months previously, and not currently participating in a diabetes clinical trial. Patients who satisfied the selection criteria were provided with an information pack and invited to opt in to the study. This resulted in a total of 24 responses to the research team. The procedure ensured that the researchers did not have access to any patient information other than that provided by respondents themselves on the consent forms.

\section{Research questions and materials}

The focus group discussions began with a general exploration of respondents' awareness, experiences, and understanding of medical research and clinical trials. They were then shown anonymised patient information sheets from three recently completed trials, and asked to discuss in detail how they would respond to such information themselves, focusing in particular on sections outlining the experimental nature and procedures of the trial, such as the random allocation process, the use of placebo if relevant, and double blinding. Before the study, the REC supplied the researchers with six information sheets. A series of standard readability tests were conducted on all six information sheets to identify three of high, medium, and low readability respectively. The three sheets were also selected to represent different trial types (see table 1).

The study was approved by a neighbouring REC to avoid any conflict of interest that may have arisen had it been reviewed by the REC that commissioned it.

\section{FINDINGS}

As part of the warm-up discussion, respondents were invited to examine their understanding of the terms "medical research" and "clinical trials". Medical research was perceived very positively and equated with a broad striving for better knowledge- "looking for a cure for cancer" — and with the more specific practice of testing drugs before releasing them on to the market. The concept of clinical trials evoked similar reactions, although with a greater emphasis on the mechanics of the process-for example, several mentioned having seen newspaper advertisements offering to pay people to take a new drug or undergo tests. It was also regarded with more ambivalence and unease than was medical research. This was reflected in the frequent use of the term "guinea pigs" and in scepticism about the motives of the commercial institutions involved:

\section{I would take it with a pinch of salt-if it's a drugs company that's in charge they've got to get something to sell.}

Respondents were then given patient information sheets to read (two per group). These were used to explore their understanding of the terms "placebo", "randomisation" and "double blinding", and how they felt about participating in a trial involving these procedures. It was immediately apparent that the technical language formed a barrier:

[Sheet A] The first paragraph's a disaster. "A randomised, double-blind study to compare the durability ..." Hello, hello-it's English I speak!

[Sheet C] It's double-Dutch. It's like when your doctor tells you there is something wrong with you and he explains it to you in medical terms. And then you say to him, "Excuse me doctor, could you explain that in layman's terms so I can understand?"

When asked specifically to concentrate on such sections in the focus groups, some respondents visibly "switched off" or struggled with the material. Although sheet A, with the

Table 1 Informed consent patient information sheets used in the study

\begin{tabular}{ll}
\hline Title of trial & Readability* \\
\hline $\begin{array}{l}\text { A: A study of Siglogasone in } \\
\text { patients with type II diabetes }\end{array}$ & Low (that is, easiest to read) \\
$\begin{array}{l}\text { not previously treated with } \\
\text { oral medication }\end{array}$ & $\begin{array}{l}\text { US school grade level } 10 \\
\text { Readability age } 15 \text { years }\end{array}$ \\
& \\
& \\
$\begin{array}{l}\text { B: A study in patients with } \\
\text { type II diabetes comparing }\end{array}$ & Medium: \\
$\begin{array}{l}\text { Taglipogasone with } \\
\text { placebo when added to } \\
\text { existing therapy }\end{array}$ & US school grade level 12 \\
\end{tabular}

Extracts from scientific information

A randomised, double-blind study

Randomised: Sometimes because we do not know which way of treating patients is best, we need to make comparisons... A computer that has no information about the individual selects the groups - that is, by chance.

Double blind: Neither you nor your doctor will know in which treatment group you are (although if your doctor needs to find out he/she can do so). This is to limit the potential for bias throughout the study.

During the study, in addition to your regular antidiabetic medication, you receive either the active study drug (Taglipogasone) or a dummy substance (placebo). This looks like the real thing but it contains no active drug.

Whether you receive the active or inactive drug will be decided by a computer, which has no information about you (that is, decided by chance). There is an equal chance of receiving either the study drug or the placebo. placebo-controlled, randomised, two-period crossover, short US school grade level 12 term safety and efficacy study Readability age 17 years of repeat oral doses of WeN 1976 in patients with diabetic neuropathy

The study medication you will receive could be either the active medication, containing the new drug WeN 1976, or a placebo (dummy tablet), which will be a substance that looks identical to the active medication but will not contain the new drug. Every patient will at some time during the study receive $\mathrm{WeN} 1976$ and placebo and the order in which you receive either $\mathrm{WeN} 1976$ or placebo will be decided at random (rather like tossing a coin).

This is called a double-blind study, which means that during the study neither you nor your doctor will know which treatment you are receiving. However, in case of an emergency, your doctor can find out what treatment you are receiving very easily.

${ }^{*}$ Calculated by averaging Flesch-Kincaid, SMOG, FOG and Fry test scores for each information sheet. 
lowest (that is, best) readability score, appeared to cause relatively fewer difficulties than the other two sheets overall, the respondents struggled with both the technical language and the scientific content in all three sheets.

\section{Understanding of the meaning and purpose of placebo}

Two of the information sheets (B and $\mathrm{C}$ ) referred to a placebo, while one (A) involved a comparison group. There was fairly widespread awareness of the term "placebo", which was understood to be a "kid-on" or "dummy tablet" administered as if it were a genuine drug but with no therapeutic effect. However, despite this surface understanding of placebo, further exploration suggested an incomplete grasp of its purpose and some discomfort with the idea of its use in practice. Comments such as "There would be no point in taking part if you know you are going to get the dummy pill. What is the point?" implied both a lack of understanding of the scientific need for the placebo, and a widely held belief that a key reason for participating in a trial was for therapeutic gain: to receive a superior treatment, alleviate current symptoms, or steady the rate of disease progression.

If your feet were sore [that is, if you suffered from neuropathy], it would help you so I would definitely go for it. It can result in amputations if you're a diabetic.

If they were offering to help keep my levels down I'd be really willing to go ahead.

This enthusiasm for trial participation in principle was tempered by the realisation, on reading the information sheet, that some participants might actually receive "nothing". In other words, the concept of using a dummy pill was acceptable if other people were the recipients but not oneself.

Another barrier to understanding was that the concept of patients receiving placebo treatment without being aware of it was implausible to respondents. It did not reflect the reality of their own experience, in which variations in treatment regimen produced instantly recognisable biofeedback:

If you are a type II diabetic and they take away your normal tablets and give you a kid-on thing-surely to [goodness] you're going to shoot up. They can't do that! Surely if you were getting the placebo you'd be as high as a kite or all over the place.

There was also considerable unease about the perceived morality of what was seen as withholding treatment from the placebo group:

Anybody who gets the placebo is going to be much worse for a start. That is not thought out. She takes a drug just now and she would have to stop and take either the placebo or the other thing and she wouldn't know which. You cannae drop the one and take a placebo 'cos your health would then go down the plug hole. I cannae see anybody doing that.

In the information sheet describing the trial that triggered these concerns, it stated that patients would receive either the placebo or the active study drug in addition to their regular antidiabetic medication, but the assumption that placebo equalled inferior care was so strong that respondents tended to persist in their interpretation even when the trial treatment details were clarified.
Only a few explanations revealed an understanding of the scientific need for placebo. The two comments below reflected minority views; one implied an awareness of the need to control for placebo effect, while the other implied an understanding of the need for meaningful comparison.

It's all to do with your head, you think you're feeling better or something like that.

It's so that when they come to the end of the trial they can say that it would appear to make a difference to those that were actually on the drug.

Those who get the real stuff should show a marked improvement.

\section{Understanding of the meaning and purpose of randomisation}

As with placebo, the respondents had a surface understanding of the concept. The notion of drawing names out of a hat or by computer was familiar, and there was general understanding from reading the information sheets of the mechanics of the process.

I think it is quite clear. I don't think there is any difference between the computer randomly selecting somebody as picking a name out of a hat. It is just telling you if you are going to take the trial then that is how it will be done.

However, few fully understood or could articulate the purpose of random allocation. Only a handful of respondents recognised that investigators and health care professionals should be removed from the selection process so that they did not, consciously or subconsciously, allocate patients in such a way as to produce favourable results:

If you look at it the worst possible way-if I wanted to sell the drugs I would pick him [pointing at hypothetical patient] because he is well behaved and does what he's telt. He doesn't eat sugar. He doesn't eat sweeties. I'd go, "I'll have him." And then [pointing at another hypothetical patient] "Oh he's on the bevry every night and eating sugar", so I'll give him the placebo. You cannae do that. It has to be completely random once you have got your group and said they are all the same.

In the following more typical exchanges, the efforts of the first respondent to explain the importance of matched groups simply did not make sense to others in the group. This appeared to be partly fuelled by a belief that the investigators would want the trial to succeed, and would therefore naturally want to pick the "best" group of people to bring this about.

Respondent $1(R 1)$ : Well that would kill the trial wouldn't it? If he picked the best subjects for the trial- "She's well behaved" - 'cos you can tell with diabetics by looking at their long-term haemoglobin whether they are good, bad or indifferent ... if it is going to be a trial, you have got to pick a group of people that are as near the same degree of Respondent 2 (R2): If they were doing the test properly they wouldn't need the computer. If he is going to do the test properly he is going to want a variety of people. He wouldn't want all the same level. He's not going to pick people at the same level. 
R1: For a trial to be of any value at all, the people have to be roughly the same in the group. You give half of them the drug and half of them not the drug. Then the results are meaningful.

R2: Aye but you might give us a placebo.

[First respondent repeats explanation]

R2: But how can you find out that it is going to help someone that is not well?

Another stumbling block to understanding appeared to be the reference to computerised participant selection and randomisation. The explanation that the computer would have no information on individuals, although presumably meant to reassure patients that there is no bias in the selection, implied a haphazard process in which one's care could be jeopardised because medical staff would not have access to full patient records.

I'm not sure about that. A person is selected to a group not knowing anything about the individual whatsoever! I would need to think or believe it was someone who knew me or who knew my medical history.

Concerns about the idea of computerised allocation were related to a general concern about "not rocking the boat" in terms of one's current treatment regimen. Respondents were keen to know that the proposed trial treatment would be suitable for them personally, that their own health status and needs would be assessed both before and throughout the trial. Although clinical trials held out the attraction of "trying something new", many were also deterred by the possibility that their health would suffer under an unknown and less suitable treatment regimen. The notion that random allocation would be conducted "by a computer which has no information on individuals" tapped into and heightened this concern.

I personally wouldn't be a guinea pig for any new drug, unless I was given an assurance that that drug was going to suit me.

If your doctor doesn't know what you're taking, he can't prescribe something else for you for your diabetes-he's got to know.

Your doctor should know what you're going to take because they could counteract each other.

At the heart of respondents' confusion about and resistance to randomisation appeared to be the dissonance between the seemingly arbitrary and remote computerised allocation process as described in the sheets and their image of the doctor-patient relationship.

I wouldn't have thought the doctor would do that [leave it to chance]. It sounds a wee bit cold.

I find that a wee bit alarming, I must say.

The idea that their doctor would wilfully not know-and by implication not care-whether they received the presumed "better" experimental treatment was disturbing.

\section{Understanding of meaning and purpose of double blinding}

Few respondents had heard this term before, and explanation of its meaning generated surprise and unease. Some worried that clinicians' ignorance of their treatment status could lead to inappropriate prescribing, or otherwise jeopardise their care; again, the notion conflicted with the importance attached to the doctor-patient relationship.

I wouldn't take part if my doctor didn't know I was taking part. I depend on my doctor. I depend on my diabetic nurse. I go every month and see her and I never miss an appointment. She tells me where I'm going wrong, if I'm doing anything wrong and how bad my level is.

As with randomisation, only a handful of respondents could venture a rationale for the double blinding. One explanation suggested the need to maintain patients' ignorance of their experimental status, while another suggested that the main purpose was to reduce potential interference and bias:

Because if the doctor knows [your status] he could start inventing - "Oh aye we'll put that down to a cold." If you showed a symptom that was against what he wanted, he can manipulate the situation.

\section{DISCUSSION}

Informed consent can be said to be seriously compromised if patients do not fully comprehend the experimental nature of the trial in which they are participating. Our study supports the large number of studies suggesting that this is likely to be the case for many people. It also shows that people assign many different meanings to written information that clinicians and investigators assume to be objective and unambiguous, and provides insights into why these different interpretations occur.

It was clear from the focus group discussions that the language used in written patient information sheets, with its dense concentration of medical and scientific vocabulary, was difficult and off-putting to these respondents. It was also apparent from the range of interpretations they offered that they had varying levels of scientific literacy. A small number, for example, demonstrated a reasonable understanding of the principles of experimentation; but many did not. The "problem" of scientific literacy in the general population is not restricted to clinical trials; a recent US survey of public understanding of science found that only $30 \%$ of respondents could be judged to have a competent understanding of the scientific process. ${ }^{18}$ Concepts such as randomisation and equipoise, like risk and probability, are particularly difficult to grasp. ${ }^{19}$ The evidence that public understanding of these concepts is highly variable raises the question, for those involved in the informed consent process, as to what level of understanding would be considered ethically acceptable. ${ }^{20}$ Should the goal be that all trial participants have sufficient literacy to understand the finer points of equipoise and randomisation, or (simply) the basic elements of a trial such as treatment regimen, trial duration, side effects, and the right to withdraw? It is arguably unreasonable and unfeasible to expect "lay" people to have the same depth of understanding as clinicians and scientists. ${ }^{21}{ }^{22}$ This is demonstrated by a study in which two hypothetical lung cancer trial scenarios were presented to samples of doctors and "lay people". ${ }^{23}$ Only $19 \%$ of the doctors versus nearly half of the lay people said they would consent to one of the trials, because "the lay people were unable to discern differences in the acceptability of clinical trials which were clear to experts in the field" (p. 388). If full understanding in all patients is probably unattainable in practice, ${ }^{4}$ the question is therefore what level of understanding is appropriate, and how this is to be assessed? 
Table 2 Examples of sample wording from Central Office for Research Ethics Committees guidelines for the development of written consent information ${ }^{25}$

\begin{tabular}{ll}
\hline Topic & Suggested sample text \\
\hline Randomised trial & "Sometimes because we do not know which way of treating patients is best, we need to \\
& make comparisons. People will be put into groups and then compared. The groups are \\
selected by a computer which has no information about the individual-ie. by chance. & $\begin{array}{l}\text { Patients in each group then have a different treatment and these are compared." } \\
\text { "In a blind trial you will not know which treatment group you are in. If the trial is a double- } \\
\text { blind trial, neither you nor your doctor will know in which treatment group you are } \\
\text { (although, if your doctor needs to find out he/she can do so)." }\end{array}$ \\
\hline
\end{tabular}

Our study suggested that limited scientific literacy was not, however, the only barrier to understanding. For many respondents, it was not simply that they did not fully understand the concepts of placebo, random allocation, and double blinding - they disliked and resisted them. The peculiar nature of the equipoised RCT whereby, contrary to a patient's expectations of medical care, doctors abdicate decisions to chance, profess to ignorance, and do not know what treatment a patient is being given, appears to pose particular barriers to understanding and acceptance. ${ }^{4}$ Thornton suggests that one explanation for patients' dislike of randomisation is its emphasis on chance rather than choice, which neglects one of the important factors in treatment and healing-patient confidence in the treatment decision. ${ }^{24}$ Snowdon et al's qualitative study of parents of seriously ill children participating in clinical trials found similar unease about the concept of randomisation. ${ }^{1}$ The parents felt that randomisation was hard to accept, using words such as "unfair", "tough" and "heartless", and maintained that it was used to save doctors from shouldering the responsibility of deciding which critically ill baby should receive the new treatment, or as a rationing tool when faced with limited resources. Some rejected the justification of medical uncertainty, arguing that doctors "should have known" which treatment was best. Parents who were assigned to the standard treatment group felt that the new treatment had been "snatched away from them" (p. 1347). ${ }^{1}$

It has been argued that apparent ignorance or misunderstanding of scientific explanation may represent a resistance to information that runs counter to one's beliefs or reduces feelings of control over one's own life. ${ }^{21}$ For example, Stockdale suggests that ignorance of genetics "is not just an absence of knowledge [but] can be a willed response to a situation ... refusal to accept or understand genetic information may be an effective coping mechanism" (p. 14l). ${ }^{22}$ The implication from Snowdon et al's study of parents of seriously ill children, and to a lesser extent our own study, is that rejection of unsettling information (such as that a patient's own doctor would wilfully not know or by implication care whether he or she received the "better" experimental treatment) is a way of maintaining one's worldview and trust in medical care in the face of apparent threats.

There are clear limits to what written information alone can do to overcome these many and complex barriers to understanding and acceptance. The quality of communication between the person obtaining consent and the patient is clearly fundamental to properly informed consent. This is a largely unobserved and unknown area. Our study does, however, highlight a number of possible areas where modest improvements may be made in written patient information. First, the study highlights the need for written information to go beyond simply explaining the mechanics of randomisation and treatment allocation to explaining, as simply and clearly as possible, why things are done the way they are. In our study, as in others, ${ }^{13}$ the respondents grasped how randomisation was performed; what they did not understand was why. Why is it important-for example, that health professionals and investigators are removed from the allocation process? Why is it necessary for some people in the trial to receive a placebo treatment?

Secondly, written information should acknowledge and address patients' unease about randomisation and other aspects of clinical trials. It should reassure the reader, for example, that care will not be jeopardised or inappropriate treatment choices made as a result of computerised allocation and double blinding.

Thirdly, national guidelines on the details of written informed consent should be revised to address the above two points. The Central Office for Research Ethics Committees guidelines for the development of written consent information ${ }^{25}$ list key headings under which information must be given, including the research methods (for example, randomisation). This is a comprehensive list that covers all the relevant medical and legal requirements. The guidelines also offer some sample sentences to describe concepts such as "randomisation", "blind", "cross-over", and "placebo" ( see table 2). Some of these were replicated or adapted in the information sheets examined in this study.

However, the guidelines could go beyond these rather mechanistic descriptions to address such questions as why it is important to avoid bias and why doctors should take no part in the allocation. They could also advise on how the "therapeutic misconception" can be minimised or avoided, and could emphasise to the producers of information that many patients find the idea of medical uncertainty troubling and unexpected. In an effort to make the explanations "easily understood by a lay person", the guidelines possibly err on the side of omitting important information or assuming that patients are unable to follow a more complex argument.

Finally, where possible, informed consent patient information sheets should be "tested" with a sample of the target audience. Testing, or "pretesting" as it is usually called, ${ }^{26}$ can be illuminating in demonstrating to the producers of information how people really respond to this information, and the gulf between what is intended and what is received. It could be used in the development of details on informed consent to assess the overall comprehensibility of the information, whether there are particular stumbling blocks to understanding, and whether the basic design, purpose, mechanics, and possible consequences of the trial are understood. Testing can also ensure that the information does not provoke undue alarm or paint too rosy a picture of the study in prospective participants' minds. This small-scale qualitative study, involving focus group discussions with small groups of patients, provides a model for how such testing could be conducted and used to enhance the quality of written informed consent information. 


\section{Authors' affiliations}

M Stead, D Eadie, K Angus, Institute for Social Marketing, University of Stirling and the Open University, Stirling, UK

D Gordon, Department of Public Health, NHS Lanarkshire, Hamilton, UK

This study was funded by NHS Lanarkshire Research Ethics Committee.

Competing interests: none declared

\section{REFERENCES}

1 Snowdon C, Garcia J, Elbourne D. Making sense of randomization; responses of parents of critically ill babies to random allocation of treatment in a clinical trial. Soc Sci Med 1997:45:1337-55.

2 Corbett F, Oldham J, Lilford R. Offering patients entry in clinical trials: preliminary study of the views of prospective participants. J Med Ethics 1996;22:227-31

3 Joffe S, Cook EF, Cleary PD, et al. Quality of informed consent: a new measure of understanding among research subjects. J Natl Cancer Inst 2001;93:139-47.

4 Edwards SJL, Lilford RJ, Braunholtz DA, et al. Ethical issues in the design and conduct of randomised controlled trials. Health Technol Assess 1998;2(15).

5 Ellis PM, Dowsett SM, Butow PN, et al. Attitudes to randomized clinical trials amongst out-patients attending a medical oncology clinic. Health Expect 1999;2:33-43.

6 Cassileth BR, Lusk EJ, Miller DS, et al. Attitudes toward clinical trials among patients and the public. JAMA 1982;248:968-70.

7 Biorn $\mathbf{E}$, Rossel P, Holm S. Can the written information to research subjects be improved? An empirical study. J Med Ethics 1999;25:263-7.

8 Sutherland HJ, Lockwood GA, Till JE. Are we getting informed consent from patients with cancer? J $R$ Soc Med 1990;83:439-43.

9 Gallo C, Perrone F, De Placido S, et al. Informed vs randomized consent to clinical trials. Lancet 1995;346:1060-4.

10 Thornton H. Understanding "informed consent". Lancet 1995;346:1047-8.

11 Simes RJ, Tattershall MHN, Coates AS, et al. Randomised comparison of procedures for obtaining informed consent in clinical trials of treatment of cancer. Br Med J 1986:293:1065-8.

12 Howard JM, Demets D, BHAT Research Group. How informed is informed consent? The BHAT experience. Control Clin Trials 1981;2:287-303.
13 Kerr C, Robinson E, Stevens A et al Randomisation in trials: do potential trial participants understand it and find it acceptable? J Med Ethics 2004;30:80-4.

14 Asai A, Ohnishi M, Nishigaki E, et al. Focus group interviews examining attitudes toward medical research among the Japanese: a qualitative study. Bioethics 2004: 18:448-70.

15 Gascon JJ, Sanchez-Ortuno M, Llor B. Treatment Compliance in Hypertension Study Group. Why hypertensive patients do not comply with the treatment: results from a qualitative study. Fam Pract 2004;21:125-30.

16 Robling MR, Hood K, Houston H. Public attitudes towards the use of primary care patient record data in medical research without consent: a qualitative study. J Med Ethics 2004;30:104-9.

17 Smith SM, O'Leary M, Bury G, et al. A qualitative investigation of the views and health beliefs of patients with Type 2 diabetes following the introduction of a diabetes shared care service. Diabet Med 2003;20:853-7.

18 National Science Board. Science and technology: public attitudes and understanding-public interest in and knowledge of S\&T. In: Science and engineering indicators-2002. (NSB-02-1) Arlington, VA: National Science Foundation, 2002:7.1-7.42

19 Featherstone K, Donovan JL. Random allocation or allocation at random? Patients' perspectives of participation in a randomised controlled trial. BM. 1998:317:1777-80.

20 Hutton JL, Ashcroft RE. Some popular versions of uninformed consent. Health Care Anal 2000;8:41-53.

21 Turney J. Public understanding of science. Lancet 1996;347:1087-90.

22 Stockdale A. Public understanding of genetics and Alzheimer disease. Genet Test 1999;3:139-45.

23 Mackillop WJ, Palmer JM, O'Sullivan B, et al. Clinical trials in cancer: the role of surrogate patients in defining what constitutes an ethically acceptable clinical experiment. Br J Cancer 1989:59:388-95.

24 Thornton H. Breast cancer trials: a patient's viewpoint. Lancet 1992;339:44-5.

25 Central Office for Research Ethics Committees (COREC). Guidelines for researchers: patient information sheet and consent form. London: COREC, 2001. http://www.corec.org.uk/applicants/help/docs/ Guidance_on_Patient_Information_Sheets_and_Consent_Forms.doc (accessed 26 Oct 2004)

26 Eadie D, Smith C. The role of applied research in public health advertising: some comparisons with commercial marketing. Health Educ $J$ 1995; $54: 367-80$

\section{bmjupdates+}

bmjupdates+ is a unique and free alerting service, designed to keep you up to date with the medical literature that is truly important to your practice.

bmjupdates+ will alert you to important new research and will provide you with the best new evidence concerning important advances in health care, tailored to your medical interests and time demands.

Where does the information come from?

bmjupdates+ applies an expert critical appraisal filter to over 100 top medical journals A panel of over 2000 physicians find the few 'must read' studies for each area of clinical interest

Sign up to receive your tailored email alerts, searching access and more...

www.bmjupdates.com 